\title{
An alternative approaches to predict flashover voltage on polluted outdoor insulators using artificial intelligence techniques
}

\author{
Ali. A. Salem ${ }^{1}$, Rahisman Abd Rahman ${ }^{2}$, M. S. Kamarudin ${ }^{3}$, N. A. Othman ${ }^{4}$, N. A. M. Jamail ${ }^{5}$, \\ H. A. Hamid ${ }^{6}$, M. T. Ishak ${ }^{7}$ \\ 1,2,3,4,5 Faculty Electrical and Electronic Engineering, University Tun Hussein Onn Malaysia (UTHM), Malaysia \\ ${ }^{6}$ School of Electrical System, Universiti Malaysia Perlis (UniMAP), Malaysia \\ ${ }^{7}$ Faculty of Engineering, National Defence University of Malaysia (UPNM), Malaysia
}

\section{Article Info}

Article history:

Received Oct 22, 2019

Revised Jan 11, 2020

Accepted Feb 14, 2020

\section{Keywords:}

Artificial neural network

ESDD

Outdoor insulators

Pollution flashover

\begin{abstract}
This paper presents an alternative approach for predicting critical voltage of pollution flashover by using Artificial Intelligence (AI) technique. Data from experimental works combined with the theoretical results from well-known theoretical modelling are used to derive algorithm for Artificial Neural Network (ANN) and Adaptive Neuro-fuzzy Inference System (ANFIS) for determining critical voltage of flashover. Series of laboratory testing and measurement are carried for 1:1, 1:5 and 1:10 ratios of top to bottom surface salt deposit density on cup and pin insulators. Insulators variables such as height $\mathrm{H}$, diameter $\mathrm{D}$, form factor $\mathrm{F}$, creepage distance $\mathrm{L}$, equivalent salt deposit density (ESDD) and flashover voltage correction are identified and used to train the AI network. Comparative studies have evidently shown that the proposed (AI) technique gives the satisfactory results compared to the analytical model and test data with the Coefficient of determination R-Square value of more than $97 \%$.
\end{abstract}

This is an open access article under the CC BY-SA license.

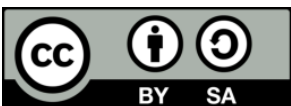

\section{Corresponding Author:}

Rahisham Abd Rahman,

Department of Electrical and Electronic Engineering,

University Tun Hussein Onn Malaysia,

86400 Parit Raja, Johor, Malaysia.

Email: rahisham@uthm.edu.my

\section{INTRODUCTION}

The exposure of insulator surface to various conditions of environmental and pollution depositions is inevitable in almost all energy systems [1-4]. Flashover on outdoor insulator occurs due to increase of electrical stresses on the transmission line combined with the high pollution level [5]. Critical voltage of flashover on polluted outdoor insulator surface is one of the important parameters for accessing reliability of a power system. Flashover prediction especially using numerical approaches have been always become a topic of interest among researchers [6]. Artificial intelligence can be used to analyses degree of pollution level, surface tracking and erosion as well as estimation of flashover occurances. In this work, data from the experimental works combined with the well- established theoretical models are utilized to develop an enhanced prediction algorithm via Artificial Neural Network (ANN) and Adaptive Neuro-fuzzy Inference System (ANFIS). Flashover voltages of polluted insulator for 1:1, 1:5 and 1:10 ratios of top (T) and bottom (B) surface ESDD on cup and pin insulators (porcelain and glass) are investigated. 


\section{MATHEMATICAL MODELS}

The process of contaminated insulators flashover has been carefully studied by several researchers. The simplest model of the pollution layer is the one developed by Obenaus which consists of an arc which shorts the dry zone in series with an equivalent resistance in the wetted area [7, 8]. Applying Ohm's law to the circuit of Figure 1.

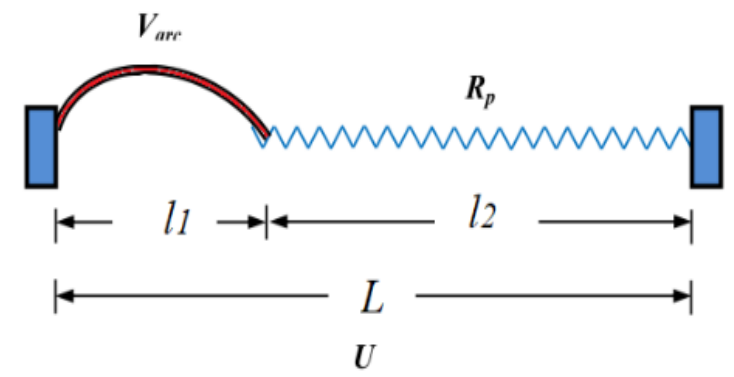

Figure 1. Equivalent circuit model of Obenaus

The voltage across the insulator is given by:

$$
U=\frac{l_{1} N}{I^{n}}+k l_{2} R_{p} I
$$

in which $l_{1}$ is the arc length, $L$ is the insulator creepage distance, $R_{P}$ is the contamination layer resistance per $\mathrm{cm}, I$ is leakage current and $N$ is the arc constants. In many cases, $R p$ can always be substituted with the conductivity, $\sigma$ of the layer of pollution. Wilkins [9] has introduced an expression (2) for the coefficient, $k$ to represent resistance of the pollution layer taking into account the current concentration at the foot point of arc.

$$
k=1+\frac{n+1}{2 \pi F n} \cdot \ln \left(\frac{L}{2 \pi F R}\right)
$$

where $\mathrm{R}$ is the arc foot radius in $\mathrm{cm}$ and $\mathrm{F}$ is the form factor. The critical voltage, $U_{c}$ and current, $I_{c}$ can be determined by using expression (3) and (4) respectively:

$$
\begin{aligned}
& U_{c}=\frac{A}{n+1}(L+\pi \cdot D \cdot F \cdot k \cdot n)(\pi \cdot D \cdot \sigma \cdot N)^{\frac{-n}{n+1}} \\
& I_{c}=(\pi \cdot D \cdot \sigma \cdot N)^{\frac{1}{n+1}}
\end{aligned}
$$

where $\mathrm{D}$ is the insulator diameter, $\mathrm{F}$ is form factor,

\section{EXPERIMENTAL WORK}

\subsection{Test insulators}

The insulators models are porcelain (XP-70) and glass (LXY-70) as shown in Figure 2. The clean and polluted insulators were tested under different parametric voltage sources. The dimension of samples are given Table 1, in which $\mathrm{H}$ is the insulator height, $\mathrm{D}$ is the insulator diameter, $\mathrm{L}$ is the leakage distance and $\mathrm{F}$ is the form factor.

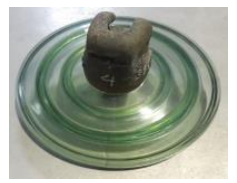

(a)

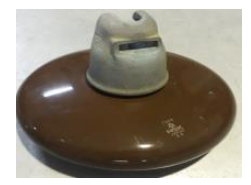

(b)

Figure 2. Insulator specimens, (a) Porcelain XP-70, (b) Glass LXY- 70 
Table 1. Dimensions of the insulator specimens

\begin{tabular}{ccccccc}
\hline Sample & Type & Materials & H/cm & D/cm & L/cm & F \\
\hline A & LXY-70 & Glass & 14.6 & 25.5 & 31 & 0.89 \\
B & XP-70 & Porcelain & 14.6 & 25.5 & 29.5 & 0.736 \\
\hline
\end{tabular}

\subsection{Experimental setup}

The experimental procedure were carried out in a different multifunctionalartificial chamber approximately $1.2 \mathrm{~m} \times 1.0 \mathrm{~m}$ and circuit arrangement is illustrated in Figure 3. The voltage was measured through AC divider of capacitive voltage while leakage current measured through shunt resistance of $10 \mathrm{k} \mathrm{ohm}$. The data acquisition monitoring system is consisting of personal computer (PC), DAQ card and LabVIEW software.

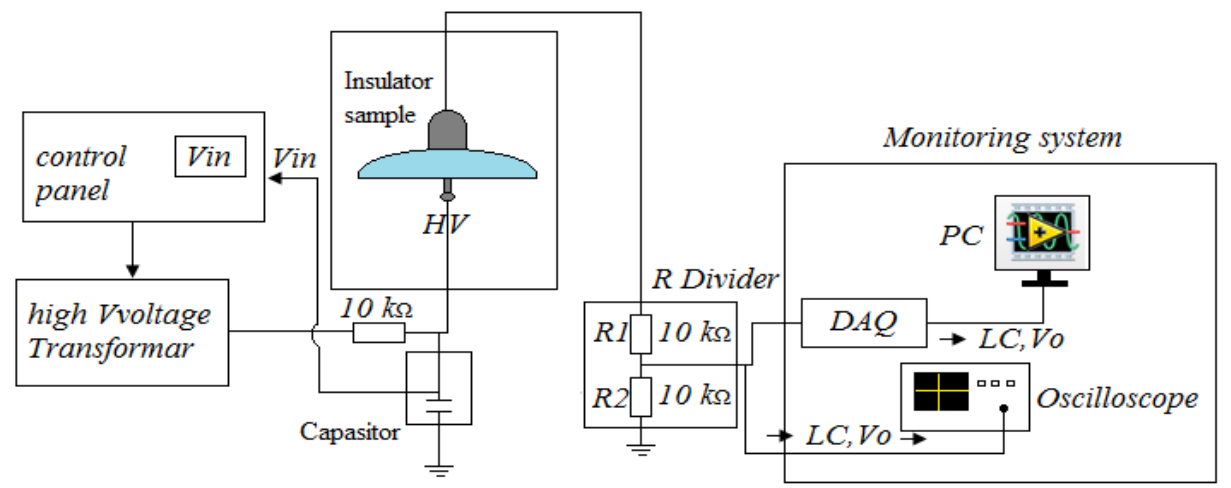

Figure 3. Block diagram of the experimental setup

\subsection{Test procedure}

Prior to the test, the insulator was first carefully cleaned using alcohol and water with conductivity lower than $10 \mu \mathrm{S} / \mathrm{cm}$. Pollution suspension is prepared by mixing an appropriate ratio kaolin with Sodium Chloride $(\mathrm{NaCl})$ in water to achieve the desired conductivity level as described in [10, 11]. The salinity of the pollution layer on the insulator is then determined using a conductivity meter. The contamination was applied according to solid layer method using brush before allowed to dry naturally for 24 hours. A sprayer is used to wet the polluted insulator sample under normal ambient condition with temperature of $25^{\circ} \mathrm{C}$ and humidity of $91 \%$. To prepare a non-uniform polluted insulator $(\mathrm{R} \neq 1)$, the top and bottom sides were polluted separately in terms of different equivalent salt deposit density $\left(\mathrm{ESDD}_{\mathrm{T}}\right.$ and $\left.\mathrm{ESDD}_{\mathrm{B}}\right)$, the average equivalent salt deposit density ESDD should be satisfied by [12]:

$$
E S D D=\frac{E S D D_{T} \cdot A_{T}+E S D D_{B} \cdot A_{B}}{A_{T}+A_{B}},
$$

where $E S D D_{T}$ represents the equivalent salt deposit density of the top side, $E S D D_{B}$ represents the equivalent salt deposit density of bottom side, $\mathrm{A}_{\mathrm{T}}$ is the top side surface area, $\mathrm{A}_{\mathrm{B}}$ is the bottom side surface area and $r$ is the ratio of pollution degree in the top side to bottom side on the non-uniform polluted insulator.

\subsection{Flashover voltage (FOV) measurment}

Severity of contamination was classified as four level are clean, light, moderate and heavy in different ESDD values as shown in Table 2. The tests of flashover were carried out on samples of cup and pin (porcelain and glass) insulators. Samples of wet polluted insulators were subjected to AC voltage source, which gradually increase until flashover occur. The results of the flashover measurement are tabulated in Table 2. The average of flashover voltage was calculated as [13]:

$$
U_{F O}=\frac{\sum_{i=1}^{N} U_{i}}{N}
$$

where $U_{F O}$ is flashover voltage, $U_{i}$ is flashover voltage carried out at $\mathrm{i}$ test, and $N$ is number of valid tests. 
Table 2. Measured voltages and current of flashover

\begin{tabular}{|c|c|c|c|c|c|c|c|c|c|c|}
\hline \multicolumn{2}{|c|}{ Insulator Type } & \multicolumn{4}{|c|}{ LXY- 70} & \multicolumn{3}{|c|}{ XP-70 } & & \\
\hline \multirow{2}{*}{$\begin{array}{c}\text { Flashover } \\
\text { Voltage }\end{array}$} & \multirow{2}{*}{$\begin{array}{c}\text { ESDD } \\
\left(\mathrm{mg} / \mathrm{cm}^{2}\right)\end{array}$} & \multicolumn{9}{|c|}{$r$} \\
\hline & & $1 / 1$ & $1 / 5$ & $1 / 10$ & $1 / 15$ & $1 / 1$ & $1 / 5$ & $1 / 10$ & & $1 / 15$ \\
\hline \multirow{6}{*}{$\mathrm{U}_{\mathrm{FO}}(\mathrm{kV})$} & 0.03 & 23.1 & 29.49 & 32.25 & 33.86 & 26.95 & 34.99 & & 38.45 & 40.48 \\
\hline & 0.1 & 13.33 & 17.02 & 18.61 & 19.54 & 20.96 & 27.22 & & 29.91 & 31.49 \\
\hline & 0.15 & 9.81 & 12.53 & 13.69 & 14.38 & 15.08 & 19.58 & & 21.51 & 22.65 \\
\hline & 0.2 & 8.67 & 11.07 & 12.10 & 12.71 & 12.22 & 15.87 & & 17.44 & 18.36 \\
\hline & 0.3 & 7.082 & 9.04 & 9.89 & 10.38 & 8.98 & 11.66 & & 12.81 & 13.49 \\
\hline & 0.35 & 6.57 & 8.39 & 9.17 & 9.63 & 8.31 & 10.78 & & 11.86 & 12.48 \\
\hline
\end{tabular}

Based on the Table 2, the results of tests show that the $U_{F O}$ of polluted insulators is decreasing as the severity of pollution is increasing. The relationship between the flashover voltage of the polluted insulator and ESDD can be expressed in (7) [14].

$$
U_{F O}=x E S D D^{-y}
$$

where $x$ is constant related to the dimensions of the insulation, type of applied voltage and the conditions surrounding the insulator and $y$ is the exponent that characterizes the impact of pollution. In non-uniform pollution case, The $\mathrm{U}_{\mathrm{FO}}$ of insulators are affected by ratio of $\mathrm{ESDD}_{\mathrm{T}}$ to $\mathrm{ESDD}_{\mathrm{B}}$ and expression (7) can be re-write as:

$$
U_{F O}=x E S D D^{-y} . C
$$

where $\mathrm{C}$ is correction of flashover voltage under non-uniform pollution and $\mathrm{A}$ is the coefficient ranges from 0.29 to 0.47 for cup and pin insulators. The correction of flashover voltage $C$ value of glass and porcelain insulators under different non-uniform pollution conditions.

\section{DETERMINATION OF ARC CONSTANTS}

The voltage across the arc have expressed in terms of Ayrton's equation as:

$$
E_{\text {arc }}=N I_{\text {arc }}^{-n}
$$

where $\mathrm{N}$ and $\mathrm{n}$ are the static and dynamic arc constants respectively. Here, $E_{\text {arc }}$ represents the arc voltage gradient and $I$ represent arc current. Most works [15-20] on polluted insulators uses characteristic arc constants $\mathrm{N}$ and $\mathrm{n}$ for various atmospheres if the discharge propagates through a humid atmosphere or in water vapor as tabulated in Table 3.

Table 3. The constants $\mathrm{N}$ and $\mathrm{n}$

\begin{tabular}{cccc}
\hline Author & $\mathrm{N}$ & $\mathrm{n}$ & Year \\
\hline Dixit et al & 68 & 0.65 & 2009 \\
Y. Sabri & 168 & 0.325 & 2010 \\
Yawei Li & $112.1(\mathrm{~T})$ & $0.82(\mathrm{~T})$ & 2014 \\
\hline
\end{tabular}

The arc constants for insulator $\mathrm{A}$ and $\mathrm{B}$ were derived from experimental data, while the mathematical relation between $E_{\text {arc }}$ and $I_{\text {arc }}$ was detemined by applying the regression method. In this study, the voltage and current arc were measured on a realcup-pin pollution standard insulators. The voltage and current of arc measured between pin as a high voltage electrode and $3 \mathrm{~mm}$ steel rod as another electrode located on the head of rib as illustrated in the Figure 4. Two arc length up to rib 2 and rib 3 representing $7 \mathrm{~cm}$ and $10 \mathrm{~cm}$ from metal conductor respectively, were chosen to be tested under different pollution levels ranging from 0.01 up to $0.35 \mathrm{mg} / \mathrm{cm}^{2}$.

The flashover voltage against ESDD experimental data can be used to compute the constants of arcmathematically for different ESDD using least square method. The results of test voltage and current of arc under different pollution severity obtained from two samples insulators are substituted in (9) resulting 
in to total of 46 equations for each insulator type. To obtain the constants of arc $\mathrm{N}$ and $\mathrm{n}, 46$ equations were simulated using 'lsqnonlin' function from the Optimization tool box in MATLAB.

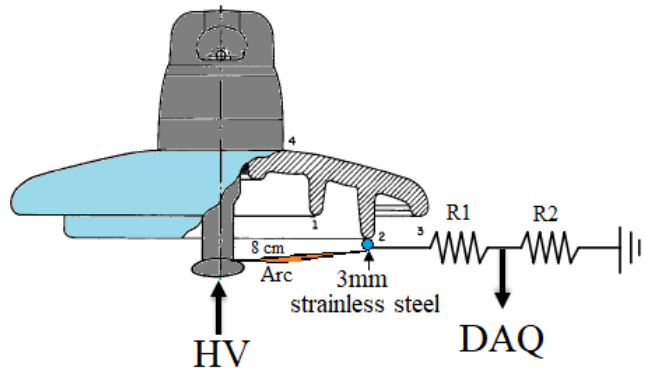

Figure 4. Schematic representation to study voltage-current behaviour of arc

\section{DERIVATION OF ARTIFICIAL INTELLIGENCE (AI)}

\subsection{Artificial neural network model (ANN)}

The severity of deposited pollution on the surface of insulators under uniform and non-uniform condition and the insulators dimension were studies in attempt to derive prediction of insulators flashover voltage using ANN [21-25]. The ANN was simulated using MATLAB R2017a Neural Network Toolbox. The six variables representing the insulator high $H$, diameter $D$, form factor $F$, creepage distance $L$, equivalent salt deposit density ESDD and flashover voltage correction under non-uniform Pollution $C$ were used as input of ANN and insulator flashover voltage as the output. The structure of ANN showed in Figure 5(a). The mathematical relationship between theinput and output of ANN can be expressed in the function form as:

$$
U_{F O}=f(H, D, F, L, E S D D, C)
$$

\subsection{Adaptive neuro-fuzzy inference system (ANFIS)}

In this work, it is assumed that ambiguous the inference system contains two inputs $x_{1}, x_{2}$ and one output, $z$ as shown in Figure 5(b). The network used in this study accepts up to six inputs parameter as the following:

$$
[x 1, x 2, \ldots, x 6]=[H, D, F, L, E S D D, C]
$$

The overall output as the summation of all incoming parameter can be expressed as:

$$
O_{5}^{i}=\sum_{i} \bar{w}_{l} f_{i}=\frac{\sum_{i} w_{i} f_{i}}{\sum_{i} w_{i}}=U_{F O}(H, D, F, L, E S D D, C)
$$

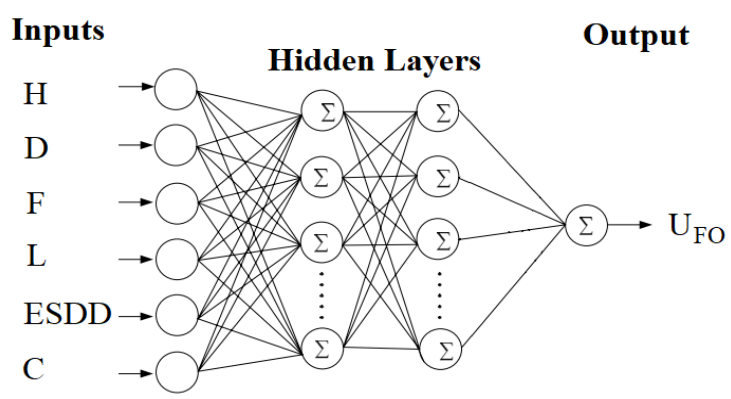

(a)

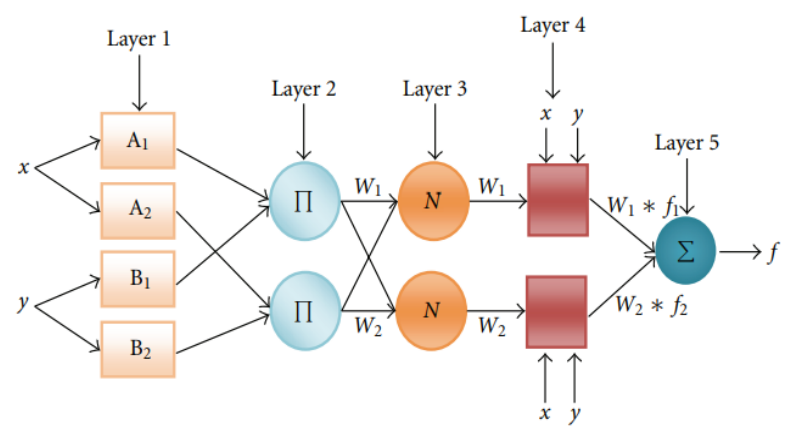

(b)

Figure 5. Schematic algorithm of, (a) ANN model, (b) ANFIS 


\section{RESULTS AND DISCUSSION}

\subsection{Earc-Iarc characteristics and arc constant ' $N$ ' and ' $n$ '}

The parameters data of arc for the highest arc length were recorded for both porcelain and glass insulators and shown in Figure 6. As can be observed, the arc voltage gradient of insulators as a function of the arc current giving exponential relationship.

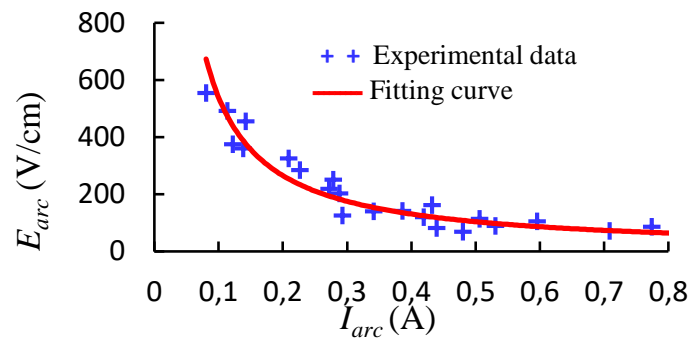

(a)

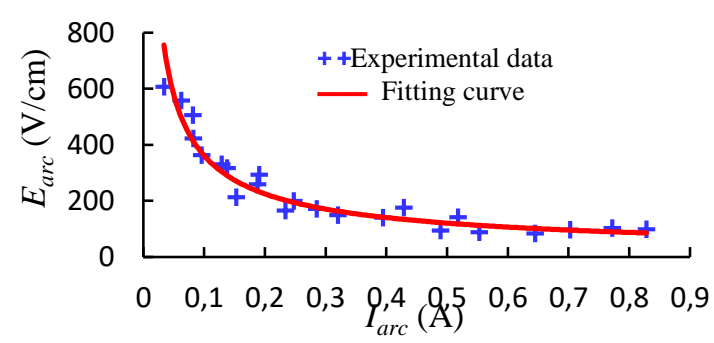

(b)

Figure 6. Earc -Iarc characteristic of, (a) Glass insulator LXY-70, (b) Porcelain XP-70

The mathematical relation of $E_{a r c}-I_{a r c} c u r v e s$ can be expressed as:

$$
E_{\operatorname{arc}(A)}=62.53 I_{\operatorname{arc}(A)}^{-0.73}(\text { for Type } \mathrm{A}), \text { and } E_{\operatorname{arc}(B)}=76.02 I_{\operatorname{arc}(B)}{ }^{-0.68}(\text { for Type B) }
$$

The calculated arc constants $(N, n)$ values of the tested insulators are summarized in Table 4 .

Table 4. Constant arc values for tested insulators

\begin{tabular}{ccccc}
\hline \multirow{2}{*}{ Type } & \multicolumn{2}{c}{ Experimental } & \multicolumn{2}{c}{ Computation } \\
\cline { 2 - 5 } & $\mathrm{N}$ & $\mathrm{n}$ & $\mathrm{N}$ & $\mathrm{n}$ \\
\hline L XY-70 & 63.08 & 0.725 & 62.53 & 0.73 \\
XP-70 & 75.37 & 0.68 & 76 & 0.68 \\
\hline
\end{tabular}

\subsection{Flashover voltage $\boldsymbol{U}_{F o}$ for polluted insulators}

Figure 7(a, b) show the plot of the relationship between flashover voltage and ESDD obtained from the experimental results under different non-uniform pollution conditions. The curve has been fitted all cases by using the exponential function expressed in (7). The results of fitting curve of $x$ value and y value were acquired under various non-uniform contamination conditions and uneven contamination degree $r$, as tabulated in Table 5. It can be observed from Figure 7(c, d) and Table 5 that the uneven contamination degree $r$ has incredible effect on the flashover voltage $\mathrm{U}_{\mathrm{FO}}$. The $\mathrm{U}_{\mathrm{FO}}$ voltage increases with an increase in the pollution ratio in the area near the high voltage terminal on the bottom surface of the insulator for both insulators. On the other hand, with decrease of $r$, the maximum of flashover voltage $\mathrm{U}_{\mathrm{FO}}$ of uniformly polluted insulator increases by $46.75 \%$ and $50.22 \%$ for the glass porcelain insulator respectively.

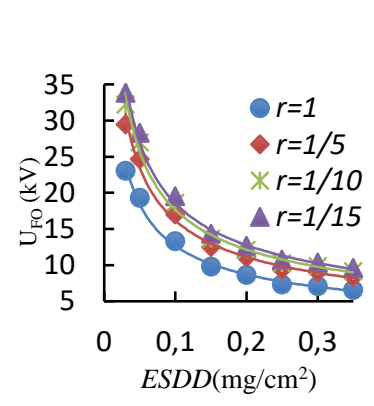

(a)

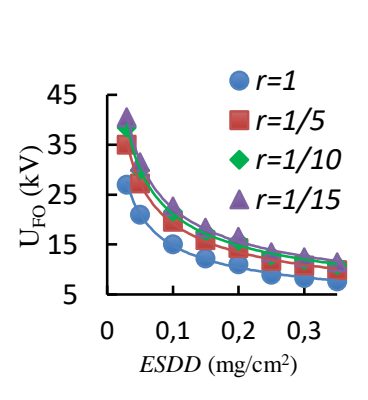

(b)

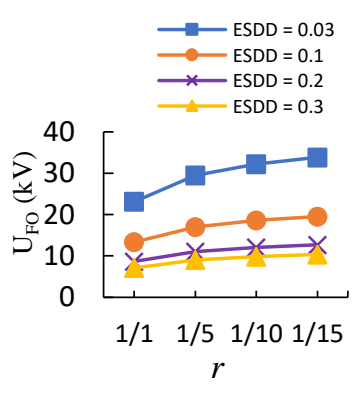

(c)

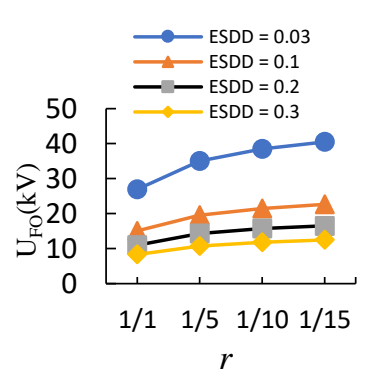

(d)

Figure 7. The trend of $\mathrm{U}_{\mathrm{FO}}$ under non-uniform pollution conditions 


\subsection{Validation of model and artificial intelligence (AI) results}

The proposed AI model is compared with Experimental and mathematical model. The comparison of the ANN, ANFIS, mathematical model and the experiment results under different non-uniform pollution condition is given in Figure 8. The comparison of different flashover voltage results obtained for the porcelain insulator under uniform pollution case is shown in Figure 9. The flashover value, $U_{F O}$ obtained from the artificial intelligence models and mathematical is compared in Figure 9. As can bee seen, the result are at good agreement to the experimental data by other researcher [4].

Table 5. Curve fitting results of $\mathrm{U}_{\mathrm{FO}}$ under different non-uniform pollution

\begin{tabular}{ccccccccccccc}
\hline $\mathrm{r}$ & & $1 / 1$ & & \multicolumn{1}{c}{$1 / 5$} & \multicolumn{3}{c}{$1 / 10$} & \multicolumn{1}{c}{$1 / 15$} \\
\hline & $\mathrm{x}$ & $\mathrm{y}$ & $\mathrm{c}$ & $\mathrm{x}$ & $\mathrm{y}$ & $\mathrm{c}$ & $\mathrm{x}$ & $\mathrm{y}$ & $\mathrm{c}$ & $\mathrm{x}$ & $\mathrm{c}$ \\
\hline L XY-70 & 3.65 & 0.54 & 1 & 4.66 & 0.54 & 1.28 & 5.1 & 0.54 & 1.4 & 5.36 & 0.54 & 1.47 \\
$\mathrm{XP}-70$ & 4.55 & 0.512 & 1 & 5.91 & 0.512 & 1.3 & 6.493 & 0.512 & 1.43 & 6.835 & 0.512 & 1.5 \\
\hline
\end{tabular}

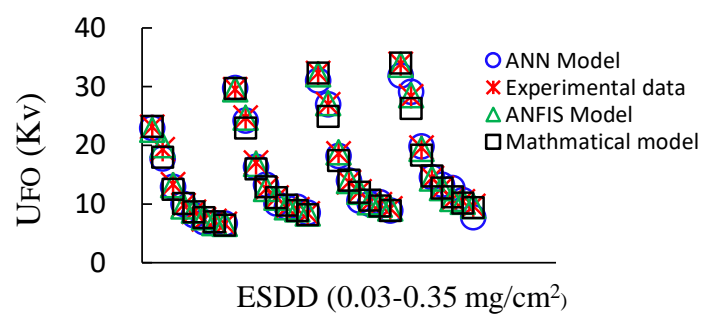

(a)

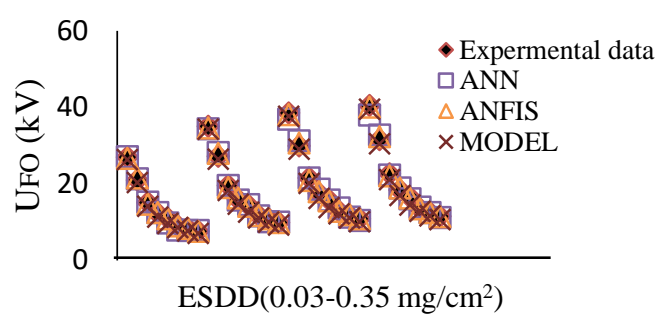

(b)

Figure 8. The comparison of AI technique models by experimental and mathmatical model results, (a) Glass, (b) Porcelian

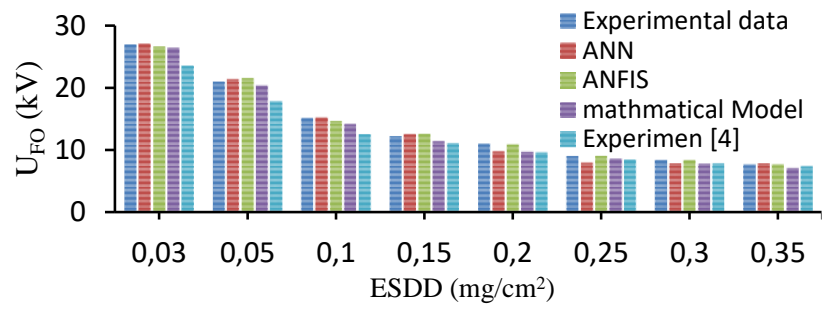

Figure 9. Comparison of $\mathrm{U}_{\mathrm{F}}$ under uniform pollution condition

\section{CONCLUSION}

This paper discusses the experimental approach and the least square simulation technique to achieve the suitable values of arc constants $\mathrm{N}$ and $\mathrm{n}$ and two artificial intelligence techniqueswere designed for the estimation of flashover voltage in artificially non-uniform polluted glass and porcelain insulators. The mathematical model based to the geometric characteristics of the insulator, ESDD and constant of arc was applied and validated using experimental flashover voltage results. Therefore, the determination of the constants of arc allows the simulation of the critical conditions for the flashover voltage. Various of non-uniform pollution cases 1:1,1/5,1/10 and 1/15 have considered in this work, these pollution conditions have a great influence on the $\mathrm{U}_{\mathrm{FO}}$. An artificial neural network has been applied to the measurement results and a good agreement has been achieved with the high determination of coefficients which is more than $97 \%$.

\section{REFERENCES}

[1] A. A. Salem and R. Abd-Rahman, "A Review of the Dynamic Modelling of Pollution Flashover on High Voltage Outdoor Insulators," in Journal of Physics: Conference Series, vol. 1049, no. 1, 2018.

[2] Thipprasert, et al.,"AC Flashover Performance for Line Post and Pin Post Insulators in Distribution 22 KV." 2012 IEEE Vehicle Power and Propulsion Conference, pp. 464-68, 2012. 
[3] Ramirez, et al. "Measurement of Leakage Current for Monitoring the Performance of Outdoor Insulators in Polluted Environments,” IEEE Electrical Insulation Magazine 28(4), pp. 29-34, 2012.

[4] R. Abd-Rahman, et al., "Dynamic modelling of polluted outdoor insulator under wet weather conditions," in PECON 2016-2016 IEEE 6th International Conference on Power and Energy, Conference Proceeding, pp. 610-614, 2017.

[5] Z. Zhang, X. Jiang, Y. Cao, et al., "Influence of low atmospheric pressure on AC pollution flashover performance of various types insulators", IEEE Trans. Dielectr. Electr. Insul,vol 2, pp. 425-433, 2017.

[6] A. A. Salem, et al., "Proposal of a dynamic numerical approach in predicting flashover critical voltage," Int. J. Power Electron. Drive Syst., vol. 10, no. 2, pp. 602-610, 2019.

[7] A. A. Salem, et al., "The effect of insulator geometrical profile on electric field distributions," Indones. J. Electr. Eng. Comput. Sci., vol. 14, no. 2, pp. 618-627, May 2019.

[8] A. A. Salem, et al., "Factors and models of pollution flashover on high voltage outdoor insulators: Review," in 2017 IEEE Conference on Energy Conversion, CENCON, pp. 241-246, 2017.

[9] M. Cebeci, et al., "Investigation of Pollution Flashover on High Voltage Insulators Using Artificial Neural Network," Expert Systems with Applications, vol. 36, no. 4, pp. 7338-7345, 2009.

[10] N. Narmadhai, et al., "Analysis of Leakage Current to Predict Insulator Flashover Using Artificial Neural Network,"Journal of computer science, vol 7, no. 2, pp. 167-72, 2011.

[11] Alawi, et al., "Prediction of Flashover Voltage of Contaminated Insulator Using ANN,"Electric Power Components and Systems, vol. 34, no. 8, pp. 831-840, 2006.

[12] Leeward. Sides, "DC Flashover Dynamic Model of Post Insulator under Non-Uniform Pollution between Windward,"Energies, vol. 12, pp. 23-45, 2019

[13] P. Dixit, et al., "Studies on Pollution Performance of Ceramic Insulators under AC excitation,"Proc. Of 16th International Symposium on High voltage Engineering, No E-35, pp. 1331-1336, 2009.

[14] D. Zhang, et al., "Effects of Soluble Constituents on Insulator Flashover Performance and Flashover Voltage Prediction,"Annual Report-Conference on Electrical Insulation and Dielectric Phenomena, pp. 165-69, 2015.

[15] L. Bo, et al., "Modeling flashover of AC outdoor insulators under contaminated conditions with dry band formation and arcing," IEEE Transactions on Dielectrics and Electrical Insulation, vol. 19, no. 3. pp. 1037-1043, 2012.

[16] A. A. Salem, et al., "A New Flashover Prediction on Outdoor Polluted Insulator Using Leakage Current Harmonic Components," 2018 IEEE 7th Int. Conf. Power Energy, pp. 413-418, 2018.

[17] Y. Sabri, M. Farzaneh and J. Chang. "Application of Methods for Predicting the Flashover Voltages of Contaminated Insulators covered with Ice," IEEE Trans. on Dielectrics of Electrical Insulation, vol. 17, no 2, pp 451-457, 2010.

[18] L. Yawei, et al., "Pollution Flashover Calculation Model Based on Characteristics of AC Partial Arc on Top and Botto Wet-Polluted Dielectric Surface,"IEEE Trans. on Dielectrics and Electrical Insulation, vol. 21, no. 4, pp 1735-1746, August 2014.

[19] S. Al-ameri, et al., "Frequency response of transformer winding to investigate the influence of RLC Frequency response of transformer winding to investigate the influence of RLC," vol. 14, no. 1, pp. 219-229, March 2019.

[20] A. G. Suresh, et al., "ANN model to predict critical flashover voltages of polluted porcelain disc insulators," Int. J. Appl. Eng. Res., vol. 12, no. 11, pp. 2942-2951, 2017.

[21] Jang, "JSR. : ANFIS Adaptive network based fuzzy inference system,"IEEE transactions on systems. Man Cybern, pp. 665-683, 1993.

[22] K. Belhouchet, et al., "Artificial neural networks (ANN) and genetic algorithm modeling and identification of arc parameter in insulators flashover voltage and leakage current," in 2015 4th International Conference on Electrical Engineering (ICEE), pp. 1-6, 2015.

[23] M. Marich, "Evaluation of flashover voltage on polluted insulators with artificial neural network,"Journal of Electrical Engineering, pp. 1-6, 2014.

[24] M. Rostaghi-Chalaki, A. Shayegani-Akmal, \& H. Mohseni, "Harmonic analysis of leakage current of silicon rubber insulators in clean-fog and salt-fog," in 18th International Symposium on High Voltage Engineering, pp. 1684-1688, 2013.

[25] A G. Suresh, et al., "ANN Model to Predict Critical Flashover Voltages of Polluted Porcelain Disc Insulators,"International Journal of Applied Engineering Research, pp.2942-2955, 2017.

\section{BIOGRAPHIES OF AUTHORS}

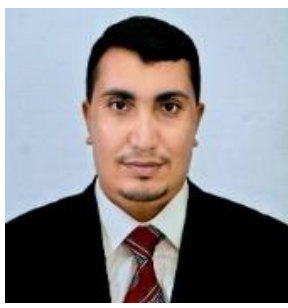

Ali Ahmed Ali Salem received B.Eng. in power electrical from Tishreen university Syria in 2010. He received M.Eng. in Electrical Power Engineering from Universiti Tun Hussein Onn Malaysia (UTHM) from 2014 to 2016. Currently he is Pursuing Ph.D. degree at High Voltage in Faculty of Electrical Engineering, UTHM. His research interest includes the dynamic arc modelling of pollution flashover on high voltage outdoor insulators. 

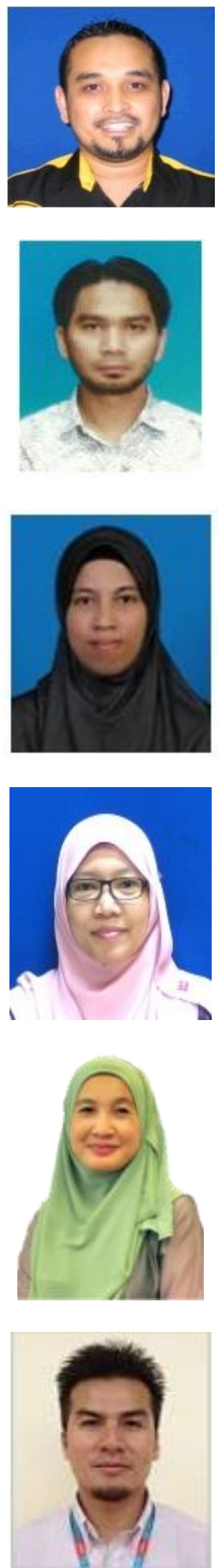

Rahisman Abd Rahman received M. Eng degree (Electrical \& Electronic) and $\mathrm{PhD}$ (High Voltage) from Cardiff University, U.K. in 2008 and 2012 respectively. He is currently a Senior Lecturer in the Faculty of Electrical \& Electronic Engineering at Universiti Tun Hussein Onn Malaysia (UTHM). His research interests include dielectric materials, outdoor insulator and discharge phenomenon. He is a Chartered Engineer U.K (CEng) and member of engineering institution such as IET (MIET), IEEE (MIEEE) as well as Board of Engineers Malaysia (BEM).

M. S. Kamarudin obtained his B.Eng. and M.Eng. degrees in Electrical Engineering (Power) from Universiti Teknologi Malaysia (UTM) in 2003 and 2005, respectively. He received his Ph.D. in High Voltage Engineering from Cardiff University, UK in 2014. Currently, he is an Associate Professor in the Faculty of Electrical \& Electronic Engineering at Universiti Tun Hussein Onn Malaysia (UTHM). He is also a Professional Engineer (Ir.) registered with the Board of Engineers, Malaysia (BEM), as well as a corporate member of the Institution of Engineers, Malaysia (IEM) and currently a member of IEEE. His research interests include gas discharges, high voltage surge arresters, as well as dielectrics and electrical insulation system.

Nordiana Azlin Othman was born in Johor, Malaysia on January 19, 1986. She received Diploma in Electrical Communication and B.Eng. in Electrical Engineering from Universiti Teknologi Malaysia (UTM) respectively in 2007 and 2010. She completed her PhD in Space Charge Distirbution at Institute of High Voltage and High Current (IVAT) in Faculty of Electrical Engineering, UTM. Her research interest includes the detection and diagnostics of partial discharge and space charge in insulation for condition monitoring.

Nor Akmal Mohd Jamail is a lecturer of Universiti Tun Hussein Onn Malaysia since 2008. She received the Bachelor degree in Electrical Engineering from Universiti Teknologi Malaysia in 2005, M.Eng in Power System from Universiti Tun Hussein Onn Malaysia in 2007 and Ph.D. in High Voltage Engineering from Universiti Teknologi Malaysia, in 2015. Her research interests include condition monitoring of polymer nanocomposite insulation for HV purpose, dielectrics and electrical insulation. She is registered with the Board of Engineers Malaysia (BEM).

Haziah Abdul Hamid received the Bachelor and master's degrees in electrical engineering from Universiti Teknologi Malaysia in 1999 and 2002, respectively, and the Ph.D. degree in electrical and electronic engineering from Cardiff University, U.K., in 2012. She is currently a Senior Lecturer and the Dean with the School of Electrical System Engineering, Universiti Malaysia Perlis, Malaysia. Her main research interests are in high voltage transients, insulation system, and earthing system.

Mohd Taufiq Ishak received the B. Eng degree in Electrical Engineering (2002) from Universiti Tenaga Nasional in Malaysia and M. Eng. in Electrical Engineering (2004) from UMIST, UK. He received the PhD degree in Electrical Power Engineering from University of Manchester, UK in 2010. Currently he is a Senior Lecturer in the Department of Electrical and Electronic Engineering, Universiti Pertahanan Nasional Malaysia. His research interests are high voltage, power transformer, asset management, lifetime prediction, renewable energy, conditioning monitoring and smart grid. 